\title{
IOT: EMERGENCY BUTTON SEBAGAI PENGAMAN UNTUK MENGHINDARI PERAMPASAN SEPEDA MOTOR
}

\author{
S. Samsugi'), Wajiran' ${ }^{2}$ \\ ${ }^{1,2}$ Fakultas Teknik dan Ilmu Komputer, Universitas Teknokrat Indonesia \\ 1,2 Jl. ZA. Pagar Alam N0. 9-11 Bandarlampung, Kode Pos 35142, Indonesia \\ Email: ${ }^{1}$ s.samsugi@teknokrat.ac.id, ${ }^{2}$ wajiran@teknokrat.ac.id
}

\begin{abstract}
Vehicle theft is now almost never separated from the news in the mass media (online / offline). Theft is not only done when the motorbike is parked, but many also directly or often called "pembegalan". From the National Police Headquarters data from May 1-15 2019, there were 226 cases of fraud. The number is known to increase by 26 cases compared to the previous period, April 15-30. Based on the problem of increased theft and seizure of motorized vehicles, an additional security system is indeed needed on the Motor. However, based on some studies that have been made, most of them make applications or security systems for motorized vehicles that are in parking conditions. For this reason, researchers develop a system that can secure the vehicle when the vehicle is in use (alive). The way the proposed tool works is by making an emergency button. When the emergency button is pressed the motor will turn off with a delay of 10 seconds. From the results of the discussion and trial, the system can be deactivated via Smartphone via the Blynk application. The emergency button can work as expected ie when the button is pressed, the motor will turn off within 10 seconds after the button is pressed (10 seconds delay).
\end{abstract}

Keywords : Button, Blynk, IoT, Theft, Security

\begin{abstract}
Abstrak
Pencurian kendaraan bermotor saat ini hampir tidak pernah lepas dari pemberitaan di media masa (online/offline). Pencurian tidak hanya di lakukan saat motor terparkir, tetapi banyak juga secara langsung atau sering di sebut pembegalan. Dari data Mabes Polri periode 1-15 Mei 2019, tercatat sebanyak 226 kasus curat. Jumlah itu diketahui naik sebanyak 26 kasus jika dibandingkan dengan periode sebelumnya, 15-30 April. Berdasarkan permasalah terhadap meningkatnya pencurian dan perampasan kendaraan bermotor, maka memang dibutuhkan sistem keamanan tambahan pada Motor. Namun berdasarkan beberapa penelilian yang telah dibuat, kebanyakan membuat aplikasi atau sistem keamanan untuk kendaraan bermotor yang sedang keadaan di parker. Untuk itu, penliti mengembangkan sebuah sistem yang dapat mengamankan kendaraan pada saat kendaraan sedang di gunakan (hidup). Cara kerja alat yang diusulkan adalah dengan membuat emergency button. Ketika tombol emergency di tekan motor akan mati dengan delay selama 10 detik. Dari hasil pembahasan dan ujicoba, sistem dapat di non-aktifkan melalui Smartphone melalui aplikasi Blynk. Tombol emergency dapat bekerja sesuai dengan yang diharapkan yaitu ketika tombol di tekan, maka motor akan mati dalam waktu 10 detik setelah tombol ditekan (delay 10 detik).
\end{abstract}

Kata kunci : Button, Blynk, IOT, Pencurian, Keamanan.

\section{Pendahuluan}

Pencurian kendaraan bermotor saat ini hampir tidak pernah lepas dari pemberitaan di media masa (online/offline). Pencurian tidak hanya di lakukan saat motor terparkir, tetapi banyak juga secara langsung atau sering di sebut pembegalan. Seperti kasus yang terjadi yaitu aksi begal sadis kembali terjadi di wilayah Sumatera Selatan. Kali ini seorang wanita yang sedang hamil sembilan bulan tewas usai dua kali ditembak kepalanya oleh komplotan begal [1]. Berbeda dengan kasus yang terjadi di Bandarlampung, tukang ayam yang menjadi korban pembegalan mengatakan adiknya ditembak begal karena diduga melakukan perlawanan untuk mempertahankan sepeda motor miliknya [2]. Biasanya aksi pembunuhan oleh pelaku begal ada yang terjadi karena perlawanan dari korban. Para korban pembegalan biasanya melawan untuk mempertahankan kendaraannya agar tidak dibawa. Dari data Mabes Polri periode 1-15 Mei 2019, tercatat sebanyak 226 kasus curat. Jumlah itu diketahui naik sebanyak 26 kasus jika dibandingkan dengan periode sebelumnya, 15-30 April. Kasus yang terjadi adalah pencurian dengan pemberatan (curat), pencurian kendaraan bermotor (curanmor), pencurian dengan kekerasan (curas), serta pencurian dengan senjata api [3].

Beberapa penelitian yang sudah pernah di buat rata-rata adalah membuat sistem keamanan untuk kendaraan yang sedang terparkir, seperti pembuatan sebuah pengaman yang bisa mematikan aliran listrik yang masuk ke koil sepeda motor. Hal tersebut merupakan langkah pengamanan 
apabila motor diparkir ditempat rawan pencurian maka sepeda motor tidak dapat hidup, dan dapat meminimalisir tindak pencurian sepeda motor [4]. Alat pengaman berbasis Arduino ini dirancang untuk mengamankan sepeda motor secara efektif karena dilengkapi dengan GPS yang digunakan untuk melacak lokasi koordinat sepeda motor tanpa dibatasi jarak [5]. Sistem keamanan ini memanfaatkan teknologi mikrokontroller arduino dan sensor HCSR501 dan HC-SR04 serta rangkaian hardware lainnya yang dipasang pada sepeda motor. Sistem keamanan sepeda motor ini bisa dikendalikan dengan smartphone android oleh pemiliknya [6]. Pada penelitian ini, Penulis merancang dan mengimplementasikan kunci keamanan pada sepeda motor untuk mengurangi resiko pencurian serta pembatas kecepatan untuk mengurangi resiko kecelakaan bagi pengguna sepeda motor. Kedua fungsi alat ini dirancang menggunakan sensor kecepatan dan mikrokontroller ATmega328 atau dikenal Arduio Uno. Diharapkan alat ini bisa bermanfaat buat warga masyarakat terutama para pengguna sepeda motor [7]. Pada penelitian ini memaparkan suatu sistem keamanan sepeda motor berbasis Arduino-Android. Sistem kemanan ini berbasis relai dan akan dikendalikan melalui smartphone dengan sistem operasi Android v4.4 (KitKat). Sistem komunikasi dirancang dengan menggunakan modul bluetooth HC-06 yang dapat diintegrasikan dengan papan mikrokontroler Arduino Uno. Detail perancangan sistem dijelaskan pada makalah ini. Hasil pengujian menunjukan jarak maksimal komunikasi bluetooth antara pengendali (smartphone) dengan sistem pada sepeda motor yaitu $10 \mathrm{~m} \mathrm{[8].}$

Berdasarkan permasalah terhadap meningkatnya pencurian dan perampasan kendaraan bermotor, maka memang dibutuhkan sistem keamanan tambahan pada Motor. Namun berdasarkan beberapa penelilian yang telah dibuat, kebanyakan membuat aplikasi atau sistem keamanan untuk kendaraan bermotor yang sedang keadaan di parkir.

Untuk itu, peneliti bermaksud membuat sebuah sistem yang dapat mengamankan kendaraan pada saat kendaraan sedang di gunakan (hidup). Sistem keamanan yang akan dirancang diharapkan dapat mencegah tindakan pembunuhan ke pada korban. Cara kerja alat yang diusulkan adalah dengan membuat emergency button. Ketika tombol emergency di tekan motor akan mati dengan delay misal 10 detik. Jadi pada saat pemilik kendaraan di todong dan diminta kendaraannya, jangan lupa tekan tombol emergency dan tinggalkan motor tersebut (segera menjauh untuk menghindari kekerasan oleh begal dan biarkan motor dikendarai perampas motor (begal). Motor akan mati secara otomatis dalam waktu 10 detik, dan akan hidup lagi jika sistem ditekan tombol reset (yang tersembunyi). Tombol reset juga dapat melalui Smartphone berbasi IoT. Sistem (motor) ini juga dapat di On/Off dari Smartphone.

Dapat disimpulkan bahwa perbedaan antara sistem yang di usulkan dengan penelitian sebelumnya yaitu dimana sistem yang akan dikembangkan diharapkan dapat memberikan keamanan bagi pengendara motor (sistem keamanan saat motor hidup atau dikendarai) untuk menghindari adanya tindak kekerasan atau bahkan pembunuhan akibat perlawanan dari pemilik kendaraan.

\section{Metode Penelitian}

Penelitian yang dilakukan merupakan penelitian dengan metode experiment. Pada tahapan penelitian ini diawali dengan pengumpulan informasi khususnya pada masalah kriminalitas tentang pencurian bahkan perampasan kendaraan bermotor melalui media masa. Dari hasil pengumpulan informasi beberapa kasu pencurian atau perampasan tidak hanya di lakukan saat kendaraan terparkir, melainkan juga perampasan saat motor di kendarai. Untuk itu dibutuhkan sebuah sistem yang tidak hanya menjaga motor saat terparkir, tetapi juga di butuhkan pengamanan saat motor di kendarai. Tahapan penelitian di jelaskan dalam Gambar 1 berikut.

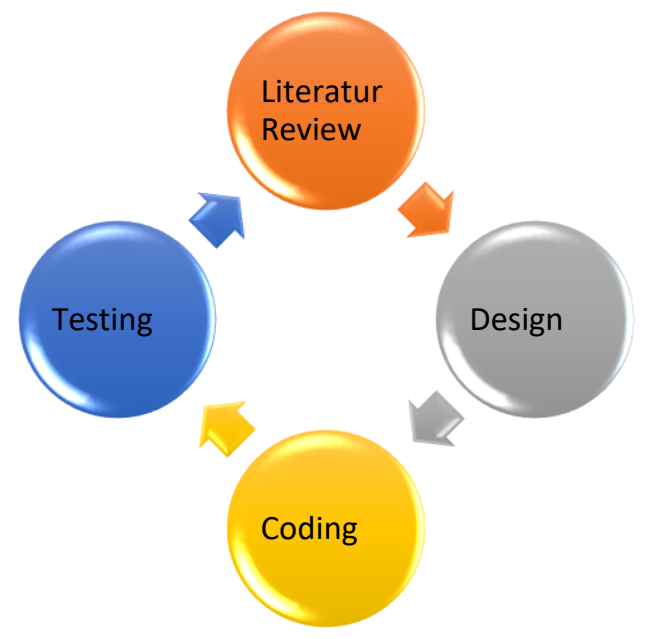

Gambar 1 Tahapan Penelitian

\section{Literature Review}

Pada tahapan ini kegiatan yang dilakukan adalah mengumpulkan informasi atau berita tentang pencurian dan perampasan terhadap kendaraan bermotor melalui media masa. Dari hail penelusuran dari media masa banyak kasus pencurian dan juga perampasan terhadap kendaraan baik itu yang terparkir maupun saat sedang dikendarai. Selanjutnya berdasarkan permasalahan yang terjadi memang sangat dibutuhkan keamanan tambahan selain dari pabrikan. Untuk itu penulis mencari beberapa penelitian terkait sistem keamanan untuk motor. Berdasarkan penelitian sebelumnya, belum adanya sistem keamanan untuk kendaraan saat motor sedang dikendarai. Selain itu juga mengidentifikasi perangkat atau komponen yang dibutuhkan dalam membuat sistem. Alat dan bahan yang dibutuhkan dapat dilihat pada tabel 1 . 
Tabel 1. Alat dan Bahan Penelitian

\begin{tabular}{|c|c|c|}
\hline No & Nama Device & Keterangan \\
\hline 1 & Arduino Uno & Sebagai microcontroller \\
\hline 2 & NodeMCU 8266 & $\begin{array}{l}\text { Koneksi ke Internet } \\
\text { yang tehubung melalui } \\
\text { aplikasi Blynk }\end{array}$ \\
\hline 3 & Internet & Koneksi IoT \\
\hline 4 & Kunci Kontak Motor & $\begin{array}{l}\text { Sebagai objek pemutus } \\
\text { pengapian dari CDI ke } \\
\text { AKI dan untuk } \\
\text { mengaktifkn sistem. }\end{array}$ \\
\hline 5 & Relay 4 in 1 & $\begin{array}{lr}\text { Untuk memutus jalur } \\
\text { CDI, mengaktifkan } \\
\text { Klaskso dan } r \text { Lampu } \\
\text { serta } & \text { untuk } \\
\text { Menghidupka } & \text { Mesin } \\
\text { melalui aplikasi } & \text { Blynk. }\end{array}$ \\
\hline 6 & Push Button & $\begin{array}{l}\text { Tombol darurat } \\
\text { (emergency) dan juga } \\
\text { untuk tombol reset. }\end{array}$ \\
\hline 7 & Klakson dan Lampu & Sebagai Output \\
\hline 8 & Saklar Starter & $\begin{array}{l}\text { Menghidupkan Mesin } \\
\text { selain dari HP }\end{array}$ \\
\hline 9 & LCD i2c & $\begin{array}{l}\text { Menampilkan Tulisan } \\
\text { dari Sistem }\end{array}$ \\
\hline 10 & Smartphone & $\begin{array}{l}\text { Sebagai alat control } \\
\text { melalaui Internet }\end{array}$ \\
\hline 11 & Aplikasi Blynk & $\begin{array}{l}\text { Sebagai antarmuka } \\
\text { antara Motor dan Sistem } \\
\text { berbasis Internet. }\end{array}$ \\
\hline
\end{tabular}

\section{Desain Rangkaian}

Setelah menyimpulkan hasil review terhadap berita maupun artikel ilmiah, tahapan selanjutnya adalah mendesain sistem yang bisa memberikan pengaman pada motor walaupun saat di kendarai. Dengan tujuan mengurangi tindak kekerasan pada pengendara. Desain sistem menggunakan aplikasi Fritzing dan untuk antarmuka android menggunakan aplikasi Blynk versi free version. Sehingga sistem dapat di kontrol melalui internet.
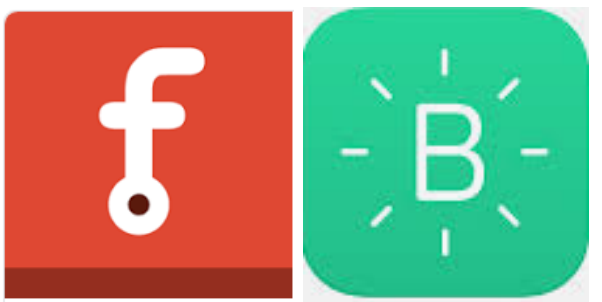

Gambar 2 Aplikasi Fritzing dan Blynk Free Version

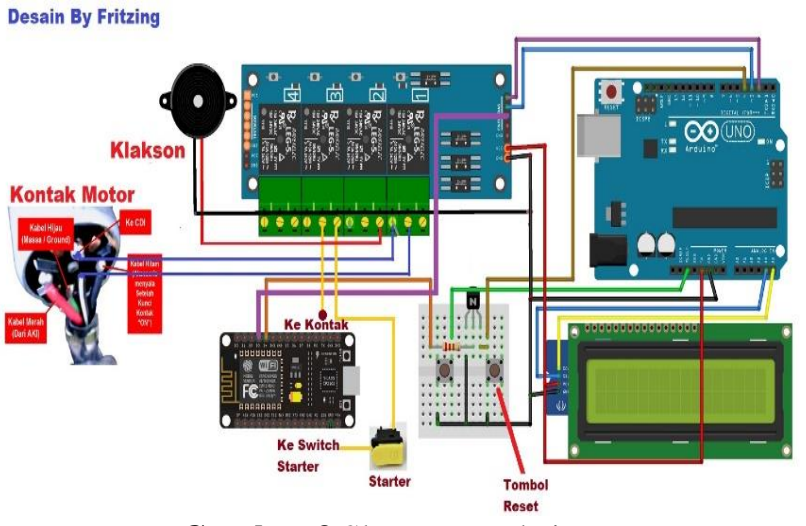

Gambar 3 Skema Rangkaian

Aplikasi Fritzing di gunakan untuk membuat sketsa rangkaian yang di instal pada PC atau Laptop. Sedangkan Aplikasi Blynk di instal pada Smartphone sebagai antarmuka kontrol sistem melalui internet.

\section{Coding}

Setelah desain atau skema rangkain telah dibuat, tahapan berikutnya adalah membuat algoritma pemrograman menggunakan Arduino IDE. Beberapa algoritma yang dibuat yaitu:

1. Algoritma button agar ketika di tekan akan menonaktifkan mesin (CDI) dalam waktu 10 detik setelah di tekan. Pada saat mesin motor mati, kemudian klakson dan lampu akan menyala.

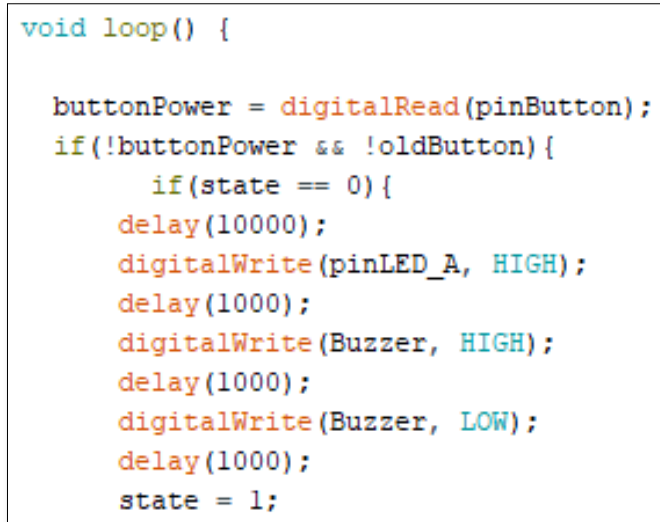

Gambar 4 Algoritma tombol stop

2. Kemudian untuk kontrol reset dapat dilakukan melalui tombol reset maupun melalui Handphone (HP) menggunakan aplikasi Blynk. Tombol reset langsung di hubungkan pada arduino pada pin reset sehingga tidak membutuhkan algoritma. Aplikasi blink dapat di unduh secara gratis pada play store melalui HP. 


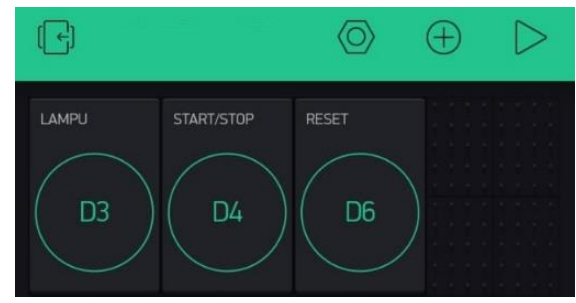

Gambar 5 Desain Antarmuka Blynk

\section{Testing}

Tahapan selanjutnya adalah melakukan ujicoba sistem yang telah di buat apakah sudah dapat berjalan sesuai yang di inginkan. Apabila belum sesuai, maka tahapan akan di ulang kembali pada tahapan pertama sampai sistem berjalan sesuai dengan yang diharapkan. Untuk lebih memperjelas cara kerja sistem, maka dapat dilihat juga melalui alur kerja sistem yang di tampilkan pada Gambar 6 sebagai berikut.

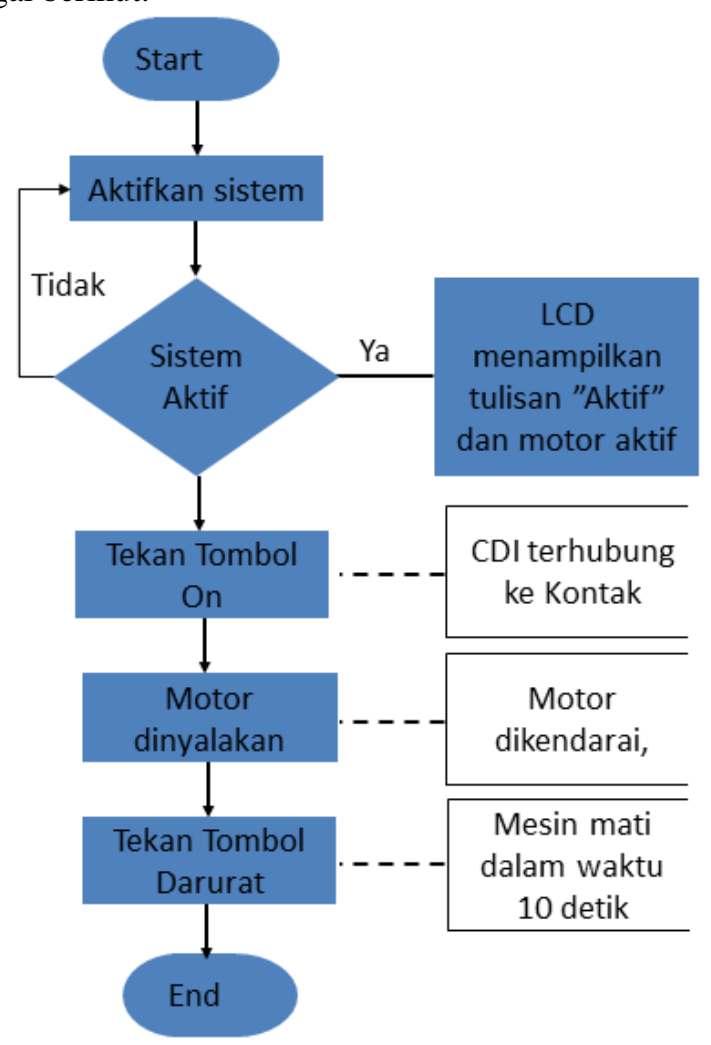

Gambar 6 Flowchar Cara Kerja Sistem

Berdasarkan hasil desain dan coding yang telah dilakuakan, dapat di jelaskan tentang cara kerja sistem yaitu:

1. Kunci kontak di aktifkn (On) maka LCD akan menapilkan tulisan Aktif, namun hanya mengaktifkan sistem, sedangkan motor belum dapat dinyalakan karena jalur kabel CDI ke Kontak masih di puutus menggunakan Relay.

2. Untuk mengaktifkan CDI, diperlukan tombol On yang dapat dilakukan baik melalui HP maupun Push Button yang sudah terpasang (tersembunyi). Apabila tombol ini di tekan, maka akan mengaktifkan Relay (CDI ke Kontak).

3. Setelah CDI terhubung ke kontak, maka mesin motor akan dapat di hidupkan melalui starter. Namun apabila tombol belum di aktifkan, maka mesin tidak akan menyala.

4. Setelah motor menyala, dapat dikendarai.

5. Pada saat terjadi keadaan darurat (misal perampasan sepeda motor) tombol darurat atau emergency button wajib ditekan. Pada saat di tekan, maka dalam waktu 10 detik mesin motor akan mati dan akan mengaktifkan lampu dan bunyi klakson. Dengan keadaan ini di harap perampas motor akan kesulitan membawa motor dan akan meninggalkan motor karena tidak bisa dinyalakan.

6. Untuk menonaktifkan klakson dan lampu, dapat menggunakan tombol reset melalui HP, namun apabila HP di rampas(keadaan terburuk), maka reset juga dapat dilakukan melalui tombol reset (tersembunyi). Sehingga motor dapat dinyalakan kembali dengan asumsi motor ditinggal oleh perampas.

Komponen yang di putus melalui relay adalah CDI dengan Kontak. CDI unit merupakan modal utama pada sistem pengapian. CDI Berfungsi untuk menyalurkan tegangan menuju coil dengan menggunakan prinsip discharge. CDI unit tersusun atas capasitor. Capasitor berfungsi untuk menyerap dan menyimpan arus listrik. Kunci kontak adalah saklar pada sistem pengapian motor CDI. Fungsi CDI kunci kontak untuk menghidupkan serta mematikan mesin. Jika kunci kontak dalam keadaan OFF maka, arus listrik tidak dapat dialirkan ke CDI [9]. Sistem pengapian motor disajikan pada Gambar 7.

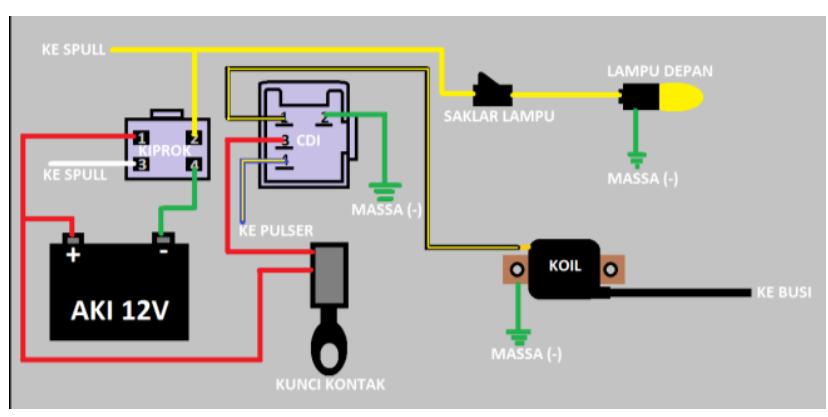

Gambar 7 Sistem Pengapian Motor (CDI)

\section{Hasil Dan Pembahasan}

Pada tahapan ini akan membahas mengenai hasil ujicoba sistem keamanan yang menggunakan tombol emergency sebagai device utama yang di gunakan untuk me-nonaktifkan mesi motor. Sebelum melakukan ujicoba ke motor, sebelumnya penulis melakukan ujicoba terhadap sistem yang telah di buat.

\section{Uji Coba Prototipe}

Tahap pertama adalah melakukan ujicoba terhadap protoipe apakah tombol darurat dapat bekerja. Pengujian 
alat dilakukan untuk mengetahui apakah fungsi-fungsi yang telah direncanakan bekerja dengan baik atau tidak [10]. Ujicoba ini belum menggunakan kontak motor dan hany menguji tombol emergency. Pada saat system di aktifkan, pada LCD akan menampilkan tulisan nama pemilik motor. Untuk prototipe ini indicator mesin menggunakan LED berwarna hijau yang berfungsi untuk menandakan bahwa sistem aktif. Setelah itu untuk mengaktifkan agar motor dapat dinyalakan dengan menekan tombol On-Off (Mesin) melalui HP atau push Button.
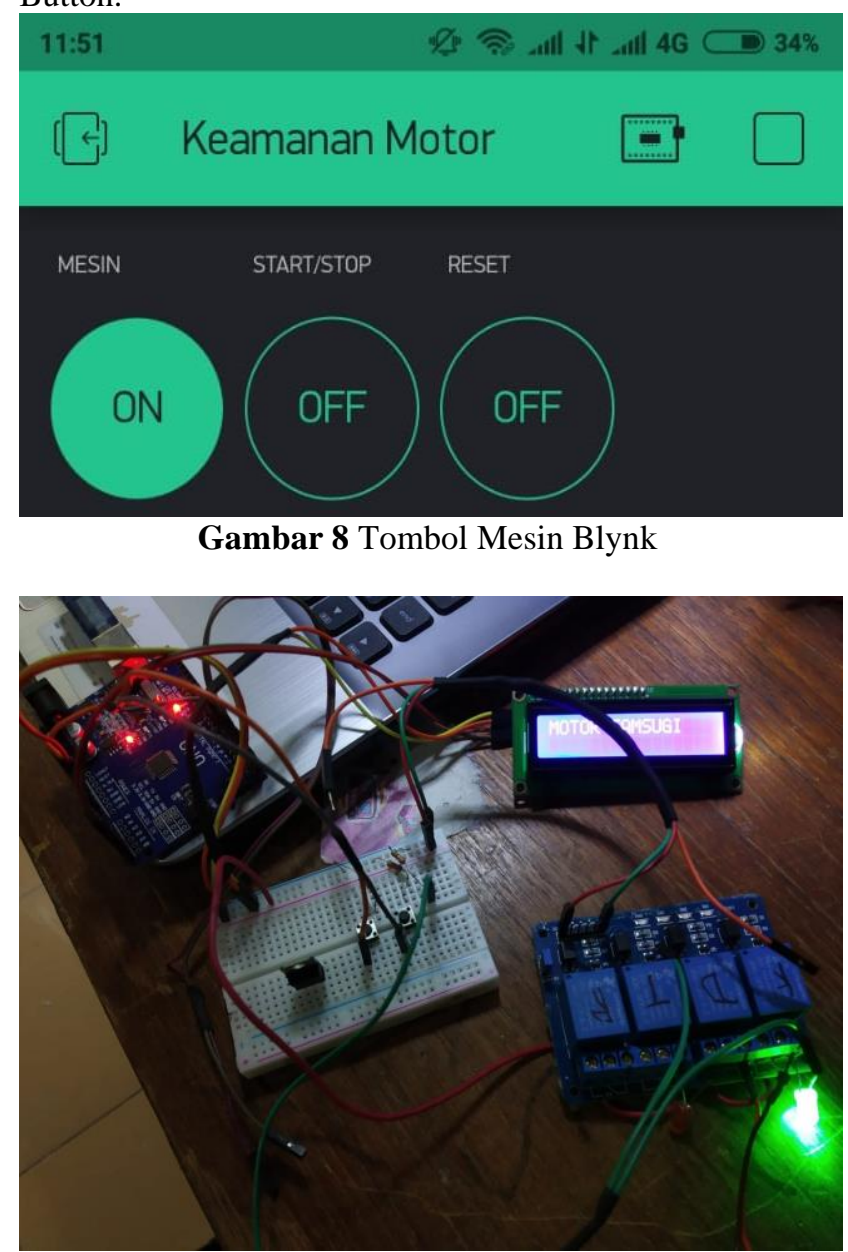

Gambar 9 Sistem dan Motor Aktif

\section{Uji Coba Tombol Starter}

Setelah sistem dan motor aktif, selanjutnya motor dapat di hidupkan (starter) yang dapat dilakukan menggunakan Tombol Starter pada Motor maupun melalui HP. Berikut tampilan antarmuka Starter pada HP. Aplikasi Blynk dapat terhubung ke sistem menggunakan fasilitas Internet dan NodeMCU esp8266 atau dikenal dengan istilah Internet of Things. Gambar tampilan antarmuka Start/Stop disajikan pada Gambar 10.

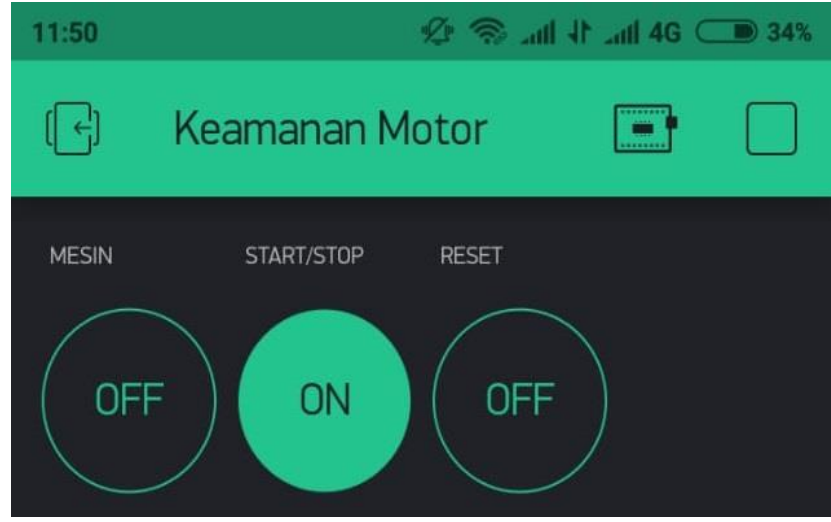

Gambar 10 Tombol Starter Blynk

\section{Uji Coba Tombol Darurat (Emergency Button)}

Pada tahap ini, pengujian dilakukan untuk mencoba apakah tombol darurat dapat bekerja setelah di tekan. Pengujian dilakukan hanya berupa Prototipe pada kendaraan berhenti.. Skenario pengujian di sajikan dalam Table 2 berikut.

Table 2. Skenario pengujian

\begin{tabular}{|c|c|c|}
\hline No & Skenario & Hasil Pengamatan \\
\hline 1 & $\begin{array}{l}\text { Mengaktifkan } \\
\text { Kontak Motor }\end{array}$ & $\begin{array}{l}\text { Bersamaan dengan } \\
\text { aktifnya Motor (dilihat } \\
\text { dari indicator pada } \\
\text { dashboard Motor), maka } \\
\text { Sistem juga Aktif. }\end{array}$ \\
\hline 2 & $\begin{array}{l}\text { Mengaktifkan sistem } \\
\text { melalui Smartphone }\end{array}$ & $\begin{array}{l}\text { Sistem pengapian (coil } \\
\text { motor) aktif }\end{array}$ \\
\hline 3 & $\begin{array}{l}\text { Menyalakan Mesin } \\
\text { Motor melalui } \\
\text { tombol starter atau } \\
\text { melalui Smartphone }\end{array}$ & Mesin Motor menyala \\
\hline 4 & $\begin{array}{l}\text { Pada saat mesin } \\
\text { menyala, tekan } \\
\text { tombol emergency }\end{array}$ & $\begin{array}{l}\text { Mesin mati dalam hitung } \\
\text { mundur } 10 \text { detik dan } \\
\text { lampu menyala, begitu } \\
\text { juga dengan klakson } \\
\text { menyala terus menerus. }\end{array}$ \\
\hline 5 & $\begin{array}{l}\text { Menekan tombol } \\
\text { emergency }\end{array}$ & $\begin{array}{l}\text { Sistem mati dan kembali } \\
\text { keadaan semula. }\end{array}$ \\
\hline
\end{tabular}

\section{Gambar Motor Aktif}

Pada Gambar 11 menyajikan saat sistem di aktifkan maka pada LCD akan menampilkan text nama pemilik motor. 


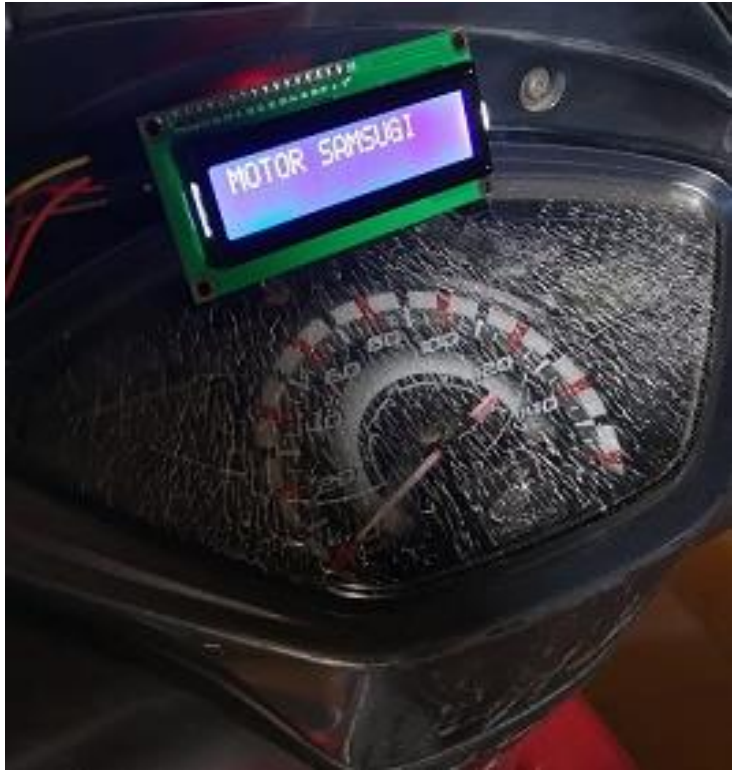

Gambar 11 Sistem Aktif

\section{Gambar Tombol Darurat (Emergency Button)}

Pada Gambar 12 menunjukan letak pemasangan tombol darurat agar mudah di akses (ditekan) oleh pengendara saat terjadi tindak kejahatan. Ketika tombol ini ditekan maka akan menghitung mundur 10 detik untuk mematikan mesin.

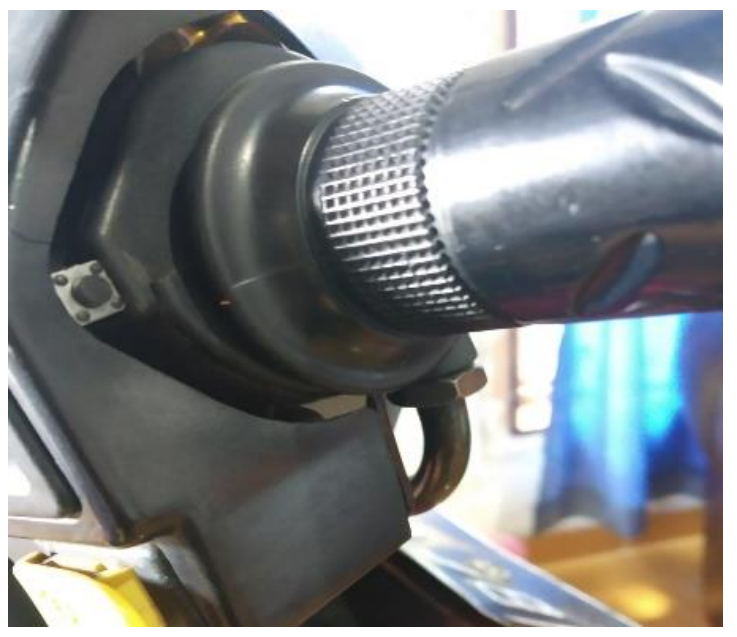

Gambar 12 Tombol Darurat

\section{Gambar Tombol Reset}

Tombol reset diletakkan pada Jok Motor. Tombol reset di gunakan untuk mengembalikan keadaan sistem motor ke keadaan semula. Karena jika tombol reset belum di tekan maka lampu dan klakson akan menyala terus menerus. Tombol reset disajikan pada Gambar 13 berikut.

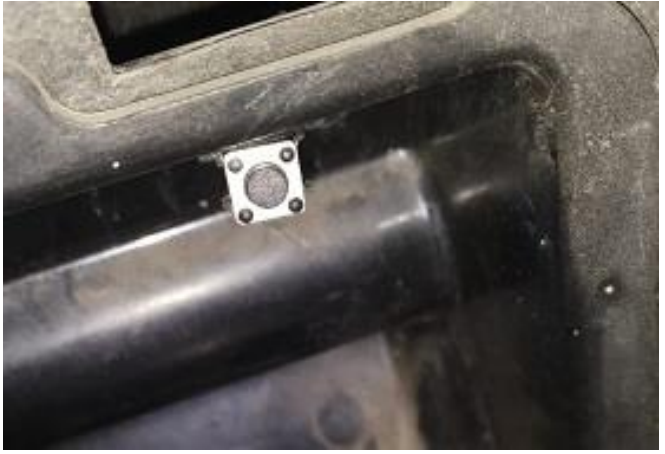

Gambar 13 Peletakan Tombol Reset

\section{Penutup}

Berdasarkan hasil pengujian sistem, dapat disimpulkan bahwa:

1. Sistem dilakukan uji coba pada Motor yang sedang dalam keadaan berhenti. Belum dilakukan pengujian saat kendaraan berjalan.

2. Sistem yang di buat dapat berjalan sesuai dengan perencanaan awal dimana ketika tombol emergency di tekan motor akan mati dengan delay selama 10 detik. Dari hasil pembahasan dan ujicoba, sistem dapat di non-aktifkan melalui Smartphone melalui aplikasi Blynk. Tombol emergency dapat bekerja sesuai dengan yang diharapkan yaitu ketika tombol di tekan, maka motor akan mati dalam waktu 10 detik setelah tombol ditekan (delay 10 detik).

Kelemahan sistem ini adalah ketika pengguna motor lupa menekan tombol darurat, maka sistem tidak dapat bekerja.

\section{Daftar Pustaka}

[1] Irwanto, "Begal sadis beraksi di sumsel wanita hamil 9 bulan tewas ditembak". Edisi senin 20 Februari 2017. sumber https://www.merdeka.com/2017.

[2] Amri, A, Berita korban penembakan begal diduga sempat melawan. Edisi 26 Oktober 2019. Sumber https://www.lampost.co/2019

[3] Data Kriminalitas Naik, sumber CNN Indonesia, edisi Jumat, 17/05/2019

[4] Suki, HR, Nurussa'adah, Zainuri,A "Implementasi Rfid Sebagai Pengaman Pada Sepeda Motor Untuk Mengurangi Tindak Pencurian",Jurnal Mahasiswa Teknik Elektro Universitas Brawijaya

[5] Pratama, D, Febriyanto, DE, Hakim, AD "Sistem Keamanan Ganda Pada Sepeda Motor Untuk Pencegahan Pencurian Dengan Smarty (Smart Security)", Jurnal Ilmu Komputer dan Informatika, Vol. 3 No. 1 | Juni 2017. 
[6] H. Sujadi and P. Paisal, "Sistem Keamanan Sepeda Motor Menggunakan Mikrokontroller Arduino Uno R3 Dengan Sensor Hc-Sr501 Dan Hc-Sr04," J. Ilm. Teknol. Inf. Terap., vol. 4, no. 2, pp. 125-130, 2018

[7] D. A. N. Tomy Okta Syaitri, Roby Rifaldi HArtanto, Tody Ariefianto Wibowo, "Kunci Keamanan Dan Pembatas Kecepatan Untuk Sepeda Motor Menggunakan Sensor Kecepatan Berbasis Mikrokontroller," pp. 41-51, 2015.

[8] I. Kholilah and A. R. Al Tahtawi, "Aplikasi ArduinoAndroid untuk Sistem Keamanan Sepeda Motor," J. Teknol. Rekayasa, vol. 1, no. 1, p. 53, Jan. 2017, doi: 10.31544/jtera.v1.i1.2016.53-58.
[9] NN, "fungsi-cdi-motor", https://www.otomotifo.com. di unduh pada 1 April 2020.

[10] S. Utama, A. Mulyanto, M. Arif Fauzi, and N. Utami Putri, "Implementasi Sensor Light Dependent Resistor (LDR) Dan LM35 Pada Prototipe Atap Otomatis Berbasis Arduino," CIRCUIT J. Ilm. Pendidik. Tek. Elektro, vol. 2, no. 2, pp. 83-89, 2018, doi: $10.22373 /$ crc.v2i2.3706 